\title{
8 Fostering Storytelling by Persons with Dementia in Multiparty Conversation
}

\author{
Jan Svennevig and Heidi E. Hamilton
}

\section{Introduction}

Telling personal stories is important for persons with dementia (PWDs), both for maintaining a sense of personal identity (Ramanathan 1995; Shenk 2005; Hamilton 2008; Hydén and Örulv 2009; Hydén 2018; Hamilton 2019) and for establishing or affirming social relations with others, such as staff and residents in care facilities (Crichton and Koch 2011) and spouses, family, and friends (Hydén 2011, 2018). However, PWDs frequently find that communicative and cognitive problems (such as finding words or recalling past events) may get in the way of participating in conversation on a par with their healthy conversation partners (Hamilton 2019; Wray 2020). As a consequence, PWDs may become relatively passive in their communication with others, taking fewer initiatives in conversation, limiting themselves instead to responses to others' questions of them (Backhaus 2018). Multiparty interactions can present special challenges, as the pace of the conversation and its more complex participation framework may make it difficult for PWDs to get the floor and hold it. A further complication may be involved if the PWD is to tell the story in a second language.

In order to counteract such problems, spouses, friends, and personal and professional carers may seek to assist PWDs in getting the floor and telling a story. Through conversational practices facilitating distributed cognition and distributed agency (Schrauf and Müller 2014; Hamilton 2019; Landmark and Svennevig, forthcoming), PWDs may find themselves in a position to make complex conversational contributions and share detailed personal experiences. Interlocutors may encourage PWDs to speak by asking questions and providing contextual clues (Williams et al. 2019) and engage in narrative scaffolding by completing and repairing utterances produced by the PWD (Hydén 2011). Even if they take on the role as primary storyteller, interlocutors may use verbal and non-verbal practices to involve the PWD in the telling and thereby construct the story as a collaborative achievement (Nilsson, Ekström, and Majlesi 2018).

However, such practices may on occasion be detrimental to the PWDs' participation and agency. Questions and prompts to tell may develop into 
test-like situations, causing problems and embarrassment for PWDs if they do not remember the requested information (Nilsson 2017). In addition, interlocutors who are privy to the details underlying a particular story may end up taking over the floor and speaking for PWDs instead of allowing them to speak for themselves (Österholm and Samuelsson 2015). The interactional challenge, then, is this: what interactional practices can conversational partners implement to assist PWDs in putting their remaining communicative resources to best use in storytelling? The current study investigates storytelling by PWDs in two extended excerpts from multiparty conversation, one from a domestic context, a sociable lunchtime conversation with friends, and one from an institutional context, a weekly meeting of an early-memory-loss support group. It focuses on the interlocutors' interactional practices that prove successful in promoting and scaffolding the PWDs' storytelling without putting them on the spot or speaking for them.

\section{Collaborative Storytelling in Conversation}

Storytelling in natural conversation is in essence a collaborative achievement and is in fundamental ways shaped by the actions of all interlocutors. Recipients are central in establishing the relevance of telling a story at a certain point in a conversation. Story prefaces generally include a slot for the recipient to accept or block the proposed storytelling (Sacks 1974). If recipients give a green light, they signal their willingness to allow the storyteller a multi-unit turn, and subsequently show their alignment as story recipients by restricting themselves to certain forms of minimal response, such as continuers, nods, and assessments (Stivers 2008). Other responses, such as clarification questions and other forms of "byplay" are generally produced in ways that minimize their intrusiveness to the progression of the story (Goodwin 1997). In cases where such byplay is prolonged, it may have serious disruptive consequences and threaten to derail the storytelling (Mandelbaum 1989). Finally, recipients are crucially involved in concluding the storytelling by displaying their appreciation of the story, thereby confirming the "tellability" of the story and its relevance to the topic of the conversation.

A special form of collaboration and coordination occurs in the presence of other participants who have epistemic access to the events reported, socalled "story consociates." As described by Lerner (1992), such participants may initiate storytelling by producing a story prompt and thereby eliciting a narrative from an interlocutor. In the body of the story, they may collaborate and take part in the storytelling by repairing potentially problematic aspects of the story or the storytelling, or by contributing parts of the story that crucially involve them as story characters, thereby taking the floor to "speak for themselves." And in the completion phase, they frequently add to the evaluation of the story by contributing their own assessment of the events reported in the story climax. 


\section{Data and Method}

The study comprises two instances of storytelling by a PWD. The first ("Passing the dinner rolls") comes from a casual conversation that occurred during a lunch in the home of the PWD ("Laura") and her husband with two invited friends. The conversation took place in Norway, but Laura, her husband and one of the friends were originally from the United States. Laura had previously been a native-like speaker of Norwegian, but at this point in time her Norwegian skills were markedly inferior to her English proficiency. The participants were all bilingual in Norwegian and English, and occasionally switched between these languages. The conversation was video-recorded by the husband according to the instructions of the researchers in the project "Language and Communication In Multilingual Speakers with Dementia" (for more details, see Svennevig et al. 2019).

The second case ("We used to be the caregivers") explores the trajectory of a story that emerged within the final few minutes of an audio-recorded weekly early-memory-loss support-group meeting. The one-hour interaction took place in an urban recreational center in the northeastern United States (for more details, see Hamilton and Baffy 2014) and included seven group members with dementia, two professionally trained group facilitators, and one visiting expert in dementia care.

The cases differ in two significant ways: 1) the type of encounter (everyday vs. institutional); and 2) the interlocutors' epistemic status (Heritage 2012) vis-à-vis the story to be told. In the casual conversation, the turn-taking and topic management were locally managed by the participants themselves. By contrast, in the institutional encounter, the professionally trained group facilitators usually held the reins of the discursive agendas: they chose topics for discussion, worked to ensure that the group stayed focused on the tasks at hand, and employed a range of discursive practices that encouraged and supported members' verbal participation. The cases also vary with regard to the epistemic status of the participants. In case 1, the story was prompted by the husband in a way that shows that he had previous knowledge of the events reported. In case 2, the story ultimately told by the PWD was not known by anyone else in the support group.

The study applies tools from Conversation Analysis (Sidnell and Stivers 2013) and Interactional Sociolinguistics (Gumperz 2015) to address realworld problems and identify possible solutions to them. By close analysis of single excerpts of naturally occurring interactions, we seek to understand the conversational mechanisms that promote or impede PWDs' storytelling in multiparty conversations and institutional talk. We use a multiple case study approach where we have purposefully selected two instances of storytelling in two very different interactions that, in our view, illustrate elements of good practice. They are "success stories" in two senses: 1) both PWDs recount aspects of relevant personal experiences to their conversational partners, thereby contributing positively to the development of the larger 
interaction; and 2) the interlocutors make use of conversational practices that effectively support the telling of these experiences.

In this way, we understand our study to be motivated by the "personhood movement" in dementia studies (cf. Kitwood 1997) in which "personhood" refers to "the person within - the reflexive, immaterial, communicable essence of a person that is located deep within the body, but that is sometimes veiled by symptoms" (Leibing 2006, 243). This move toward a focus on personhood is typically accompanied by a heightened interest in applying the findings of basic research to help PWDs and those who care for them, for example, by enhancing communication and lifting self-esteem. We align ourselves with most scholars in this area by focusing on the identification of active coping strategies and the enhancement of the social environment for the PWD.

\section{Passing the Dinner Rolls: Previously Known Story Told Within an Informal Setting}

The first case comes from a lunch conversation in the home of the PWD Laura (L) and her husband Gary (G), with their friends Anne (A) and Berta (B). Prior to the first extract, Anne excuses herself for stretching over to reach a plate of cheese, and Gary replies that the table is one that "requires long arms." Anne confirms by rephrasing this as "pension arms" - a Norwegian expression used to refer to stretching across the table when reaching for food. At that point, Gary turns to Laura and produces an explicit story prompt. As will become clear later on, the story relates to the problem of serving oneself when sitting at a large table: ${ }^{1}$

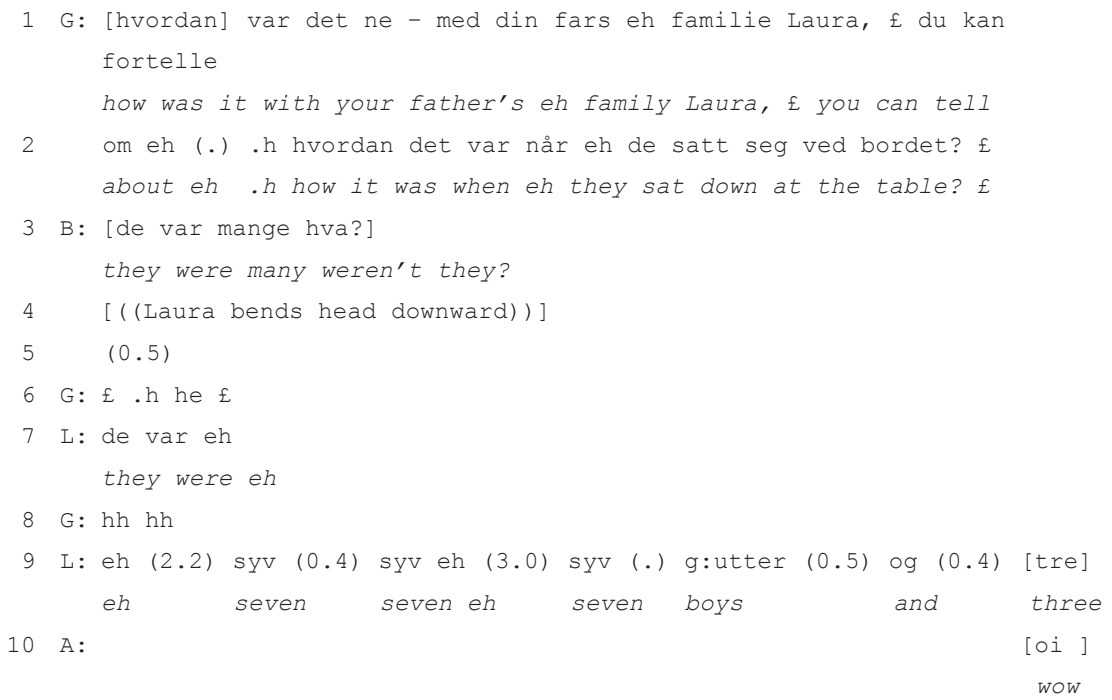




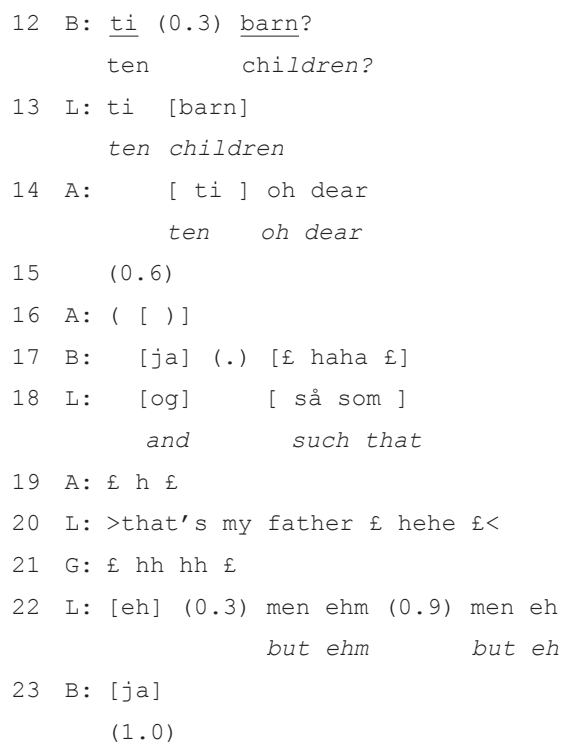

Gary's story prompt involves a reference to sitting down at a table, thereby displaying that the projected story is relevant to the topic of the prior talk and occasioned by it. This story preface shows that he is a "story consociate" but he orients to Laura's epistemic rights to tell the story by placing it within her primary epistemic domain (Raymond and Heritage 2006). $\mathrm{He}$ also gives her and the other participants a cue to identifying the type of story being projected by using a smiley voice and continuing to laugh in two subsequent pauses (lines 6 and 8). At the end of his utterance, Laura displays recognition by bending her head downward as if bursting into laughter (line 4). By producing this story prompt, Gary takes the role of a "broker," identifying the opportunity for Laura to make a relevant contribution to the conversation and inviting her to do so without speaking on her behalf.

At this point, the projected next action is for Laura to tell the story. However, simultaneously, Berta asks a clarification question eliciting background information relevant for understanding the projected story, thus initiating an insertion sequence (Schegloff 2007). As noted above, the preference for progressivity implies that such "byplay" is minimized in the service of returning to the main sequence and advancing the original project. However, Laura's answer generates expressions of astonishment (lines 10-14) and laughter (line 17) by the friends, which in turn leads Laura to expand the sequence further by producing a humorous comment about her father, code-switching to English (line 20). ${ }^{2}$

In line 22, Laura she seems to be marking a return from the insertion sequence in that she recycles the contrastive discourse marker "men" (but), which is commonly used as a resumption marker after temporary excursions 
from the main sequence (Mazeland and Huiskes 2001). However, the recycling and the subsequent pause (line 23) display trouble in resuming the main sequence. And at this point, Anne produces a question related to Laura's family:

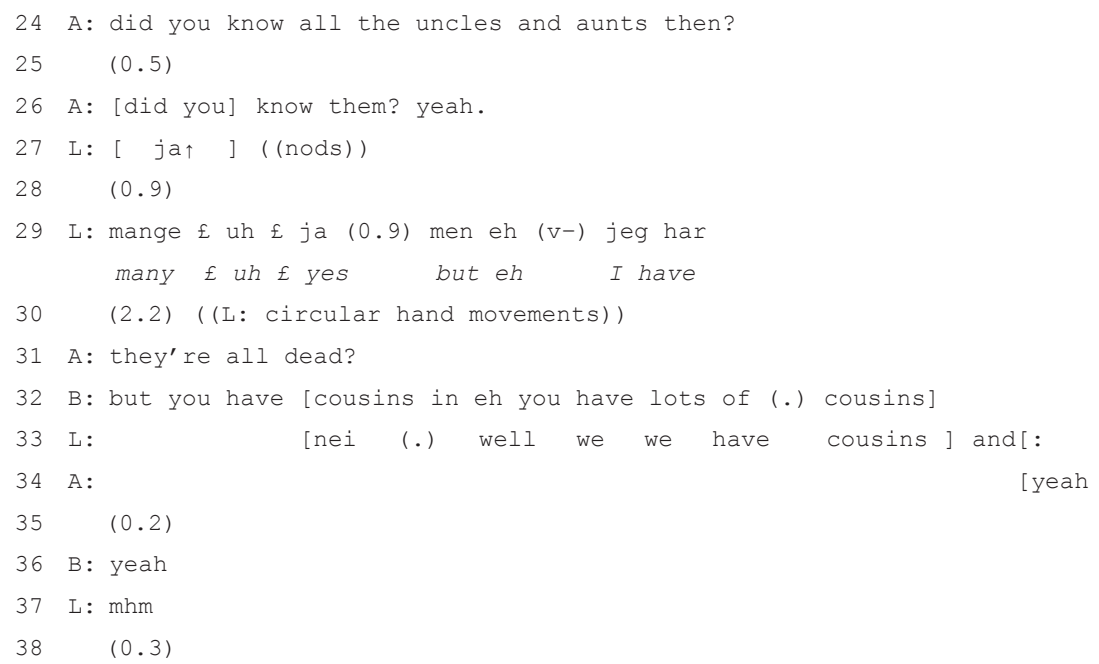

As we can see, the friends ask a series of questions about Laura's relatives, continuing in English. Laura answers the questions one by one. By continuing to ask questions related to the topic of the insertion sequence, the friends contribute to expanding it at the expense of letting Laura resume the storytelling activity. Questions like these may well be "well-intended," that is, oriented towards inviting participation by Laura, but in practice they seem to derail the storytelling. Toward the end of the excerpt, Laura does not try to resume the storytelling activity in the pauses that ensue (lines 35 and 38), and thus seems to have lost track of the story. At this point, Gary repeats his story prompt, and marks the resumption of the original activity by codeswitching back to Norwegian.

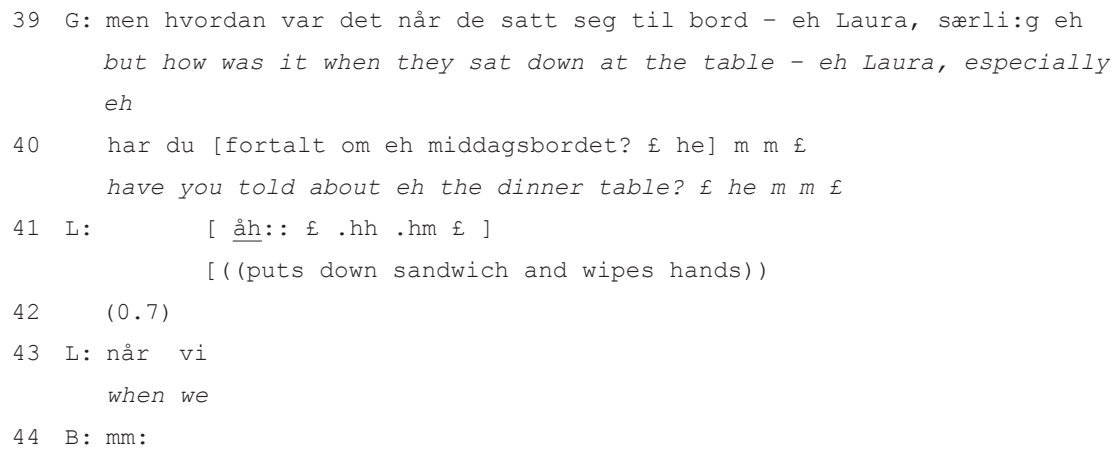




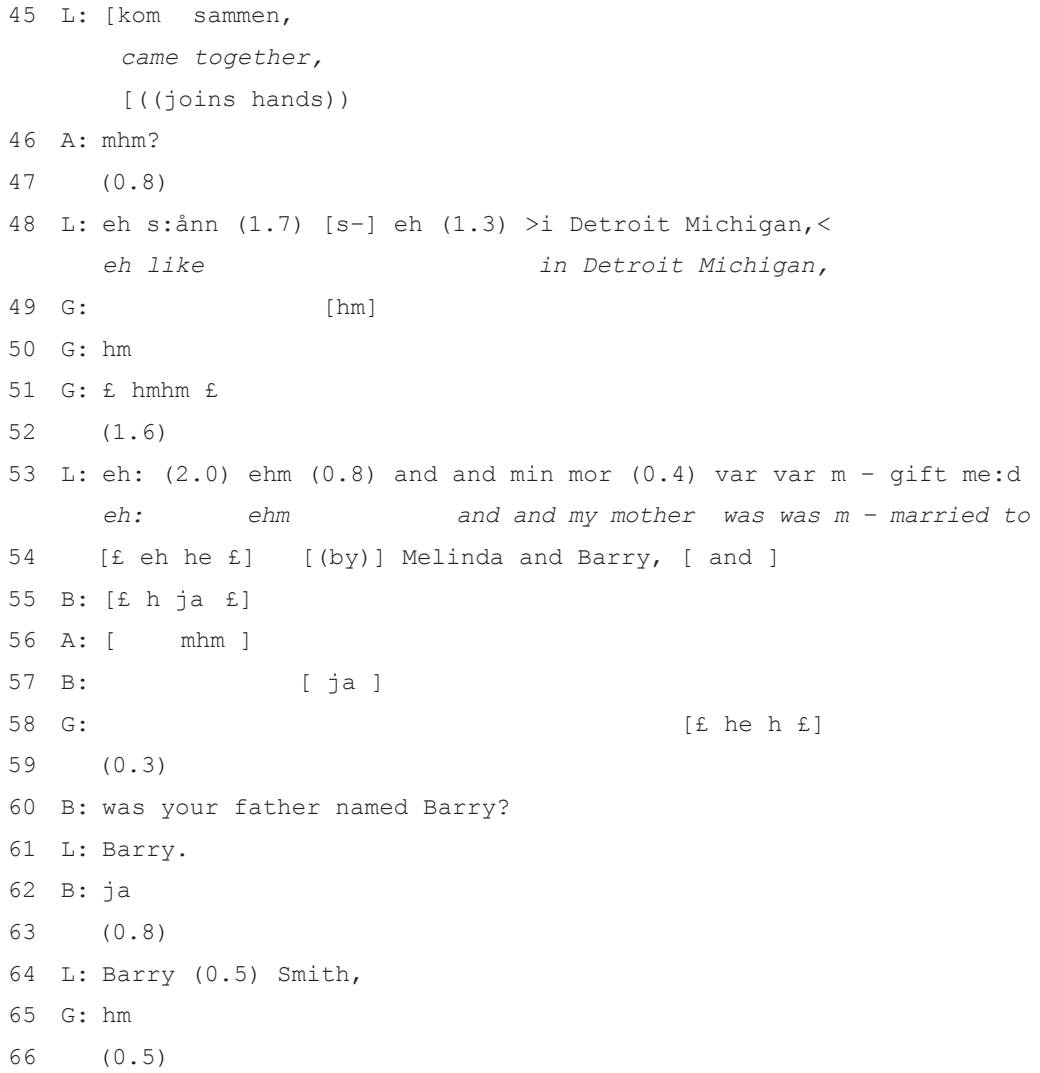

Gary's renewed story prompt effectively brings Laura back on track. This time, she makes a stronger display of recognition by producing a prolonged change-of-state token (“åh" - "oh”), indicating "now-remembering” (Seuren, Huiskes, and Koole 2016), followed by laughter tokens (line 41). She also displays readiness to start telling by putting down her sandwich and wiping her hands against each other, as if preparing for a new activity. She then starts producing what is hearably the prompted story, as it starts with the temporal subjunction "when," linking back to Gary's question about how it was "when they sat down at the table." ${ }^{3}$ This time, both Anne and Berta align as story recipients by producing continuers and letting her speak without interruption, despite her rather slow speech rate and the prolonged pauses. Gary aligns in a somewhat different way, producing short spurts of laughter (lines 49-51 and 58). As noted by Lerner (1992), story consociates may produce anticipatory laughter in order to project for the recipients a "laughable" in the upcoming talk. This seems particularly appropriate here since Laura at these points seems to deviate from the story by providing seemingly irrelevant details about the place and the participants (the story is about her father's childhood, and thus from a time long before he 


\section{6}

married). Gary's anticipatory laughter may thus not only be foreshadowing the humorous point to the recipients, but also to Laura, in order to assist her in staying on track with the storytelling. Laura again switches back to English in line 54 and this remains the language for the rest of the story. As in the previous extract, one of the friends poses a question (an understanding check) that contributes to topicalizing the information provided in this digression (line 60). In this way, Laura is once more distracted from the storytelling activity. However, as can be seen in the next excerpt, this time she manages to close the side sequence and return to the main sequence on her own:

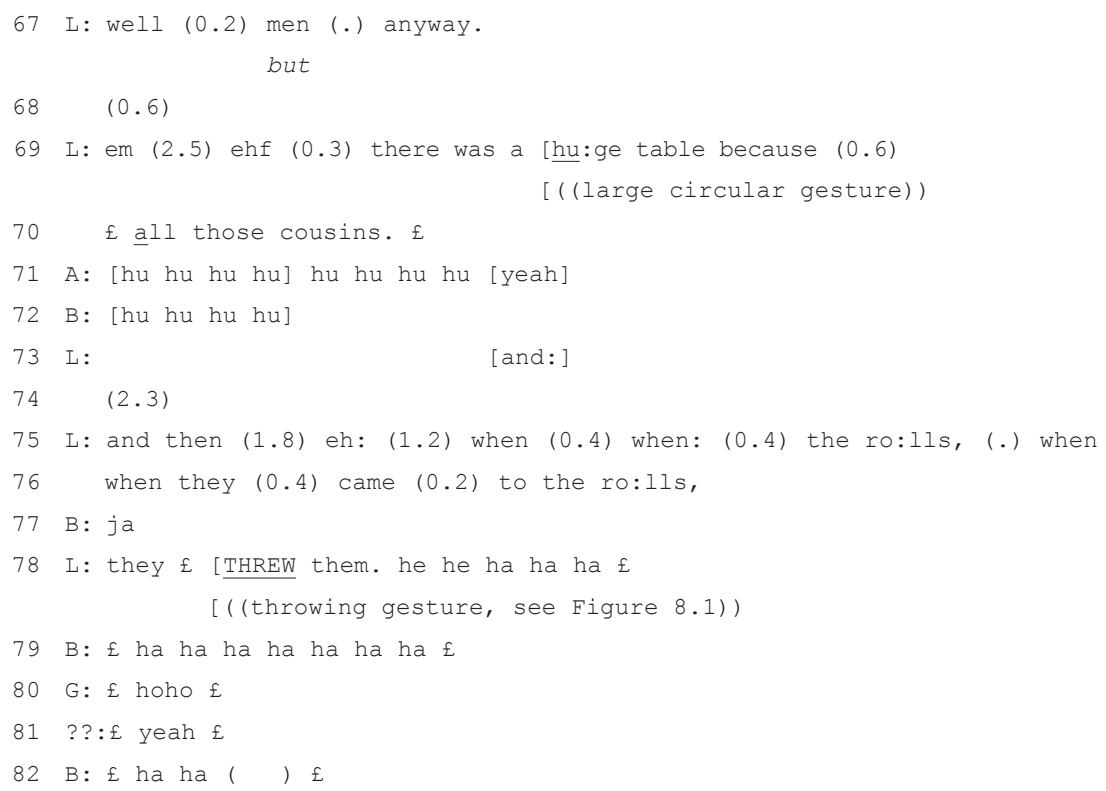

At the start of the excerpt, she produces several resumption markers, first in Norwegian ("men") and then in English ("anyway"), both signaling a return from the temporary excursion from the storytelling (Ottesjö 2005). And this time, she manages to keep the floor and advance the story, despite apparent production problems, leading to several prolonged pauses and self-repairs. At one point, she produces an utterance ("all those cousins") with laughter voice while leaning forward and gazing at Berta (line 70). Such displays of affective stance are commonly used in story climaxes (Selting 2017), and given that the projected point was a humorous one, Anne and Berta seem to treat this utterance as a potential punch line. They start to laugh, but Gary notably withholds any vocal response and thereby contributes to rejecting this interpretation of the turn. Laura then resumes the storyline by inserting the conjunction "and" (line 73), which gives her back control over the floor and projects continuation of the story. In the following extended pause 


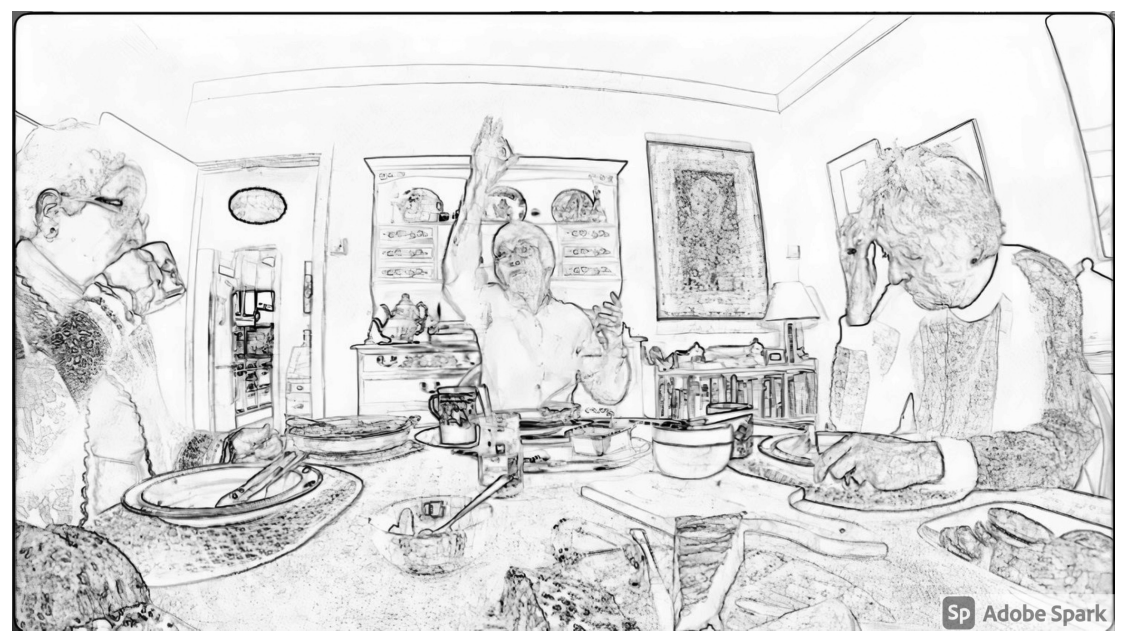

Figure 8.1 Throwing gesture

(line 74), the friends orient to this by withholding any talk. When Laura now comes to the punch line of the story, she marks heightened involvement by using laughter voice, high volume, and a large throwing gesture (Figure 8.1). This is an even more marked affect display and this time both the friends and Gary respond with extended laughter. The story may thus be considered successful in that Laura manages to deliver on her own the humorous point projected in Gary's story prompt.

What we can observe in this extract is thus a PWD who manages to contribute to a multiparty conversation with a humorous story that generates laughter. In doing so, she is prompted and helped by her interlocutors, but also distracted and derailed. The practices that promote the storytelling are primarily the husband's prompts. By asking her to tell a specific story, he both prompts her memory and gives her the floor in order to tell it. He thus does not speak on her behalf, even when she is derailed into talking about seemingly irrelevant matters. He consequently orients to her epistemic primacy and encourages her independent participation in the conversation. Furthermore, he also gives her time to talk, despite the slow pace and the many pauses, hesitations, self-repairs, and digressions that threaten the progressivity of the story and constitute points where interlocutors would typically enter into the speaker's turn space with collaborative completions or competing contributions. His continuers and laugh particles, produced as she speaks, align him as a story consociate and encourage the development of the story.

The practices that seem to complicate and derail the storytelling are primarily the questions asked by the friends. Some of the questions are understanding checks (lines 12 and 60), which deal with a potential comprehension 


\section{Jan Svennevig and Heidi E. Hamilton}

problem and thereby merely create a temporary suspension of the storytelling. But others, like the ones in lines 24,31 , and 32, topicalize matters that are recognizably not part of the storyline and thus propose a gradual topic shift to ancillary matters. These questions have the effect of derailing the storytelling in course. Also Gary's code-switching to Norwegian when renewing his story prompt seems to complicate the task, as Laura repeatedly switches back to her stronger language, English. For multilinguals with dementia, using their full linguistic repertoire may enhance their participation in communication (Svennevig et al. 2019).

\section{5 "We Used to Be the Caregivers": New Story Told Within an Institutional Setting}

The second case comes from the final few minutes of a one-hour weekly early-memory-loss support-group meeting in an urban recreational center in the northeastern United States. In contrast to the case examined above - in which a woman with dementia is prompted by her husband to tell a story known to both of them to friends over lunch in her home - in this excerpt, we follow the trajectory of a single utterance "we used to be the caregivers" (line 19) as it emerges and unfolds into a story within this institutional interaction involving seven individuals with dementia (although most do not contribute verbally to this excerpt), two experienced and professionally trained support-group facilitators, Abby and Nadine, and a visiting expert in dementia care, Mary.

Most of the hour-long interaction comprises extensive turns-at-talk by five support-group members as they respond to Mary's question "What is it like for you all to live with Alzheimer's (.) dementia (.) memory loss?" In these turns, members provide vivid and multi-faceted insights into their lived experiences with memory loss, touching on stigma and embarrassment, associated changes within the family, and descriptions of activities that bring joy into their daily lives.

Leading up to the excerpt below, facilitator Abby shifted the discourse topic away from this focus on PWDs towards a description of facilitators' work with PWDs' family members to help visitor Mary understand additional facets of dementia care at the recreational center. In lines 1-2, facilitator Nadine summarizes this aspect of their work for Mary while deftly including group members as addressees through her shift in pronoun use from third person to second person (i.e., by referring to "you guys" and "your families" in line 2; note the contrast to Abby's use of "their caregivers" in line 3).

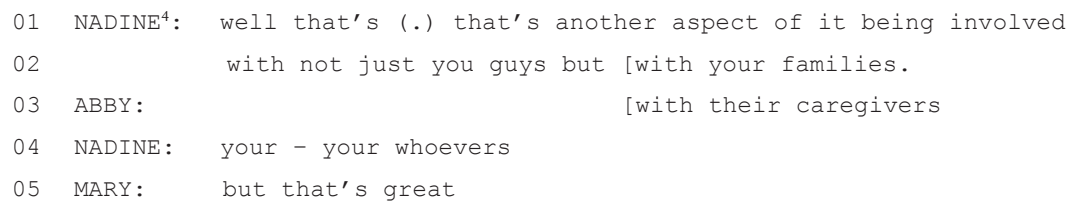




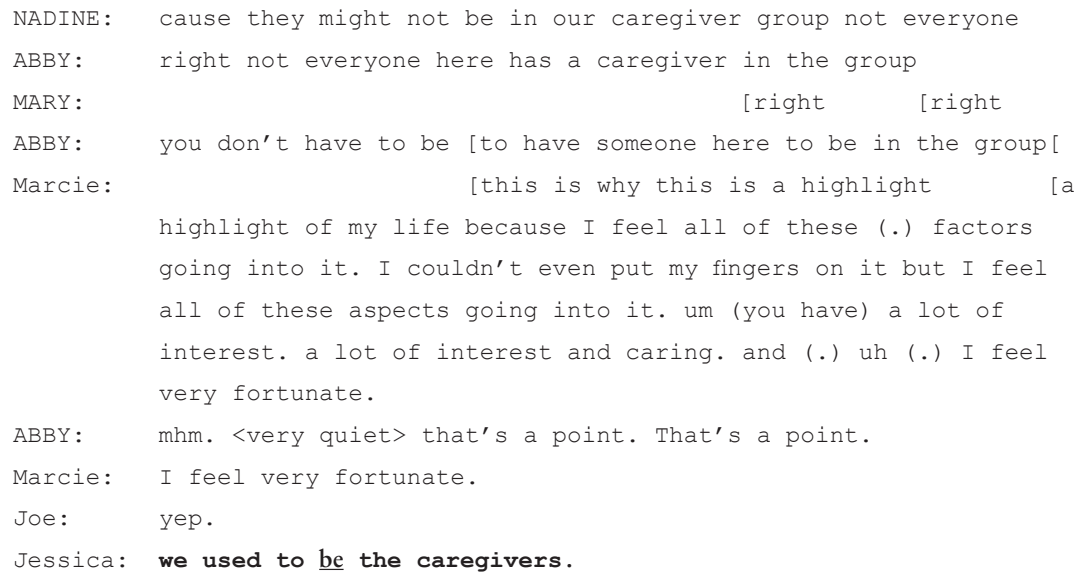

As Abby, Nadine, and Mary work toward topic closure by clarifying the connections and distinctions between the two groups with which they work, Nadine introduces the term "caregiver group" in line 6 (perhaps picking up on Abby's use of the term "caregivers" in line 3 that overlaps her own term "families" in line 2). At this point, group member Marcie takes the initiative to reenter the discussion by drawing a link ("this is why" in line 10) between her strong positive stance toward the support group ("highlight of my life" in lines 10-11; "I feel very fortunate" in lines 14-15 and 17) and how the facilitators had described their work ("all of these factors" in line 11; "all of these aspects" in lines 13) to Mary. Following validating turns by facilitator Abby and support-group member Joe, Jessica introduces a comment in the form of an unadorned assertion about how things had been in the past: "we used to be the caregivers" (line 19). This utterance displays a rather high degree of conversational agency. First, it reintroduces the topic of caregivers after a sequence that had moved the discussion in a different direction. Second, it recontextualizes it by shifting the focus from the group members' role as recipients of care to their role as providers of care (note the contrastive stress on "be").

Given that the comment is uttered at very low volume and lacks specific cohesive ties to what Marcie had just said, Jessica's utterance could quite easily have been "left out to dry," resulting in what frequently happens when PWDs attempt to enter fruitfully and fully into ongoing multiparty interactions. In this instance, however, fellow group member Marcie keeps Jessica's contribution alive by initiating a brief repair sequence (lines 20-21).

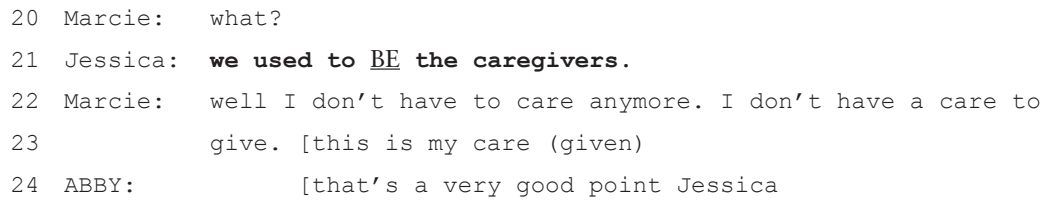




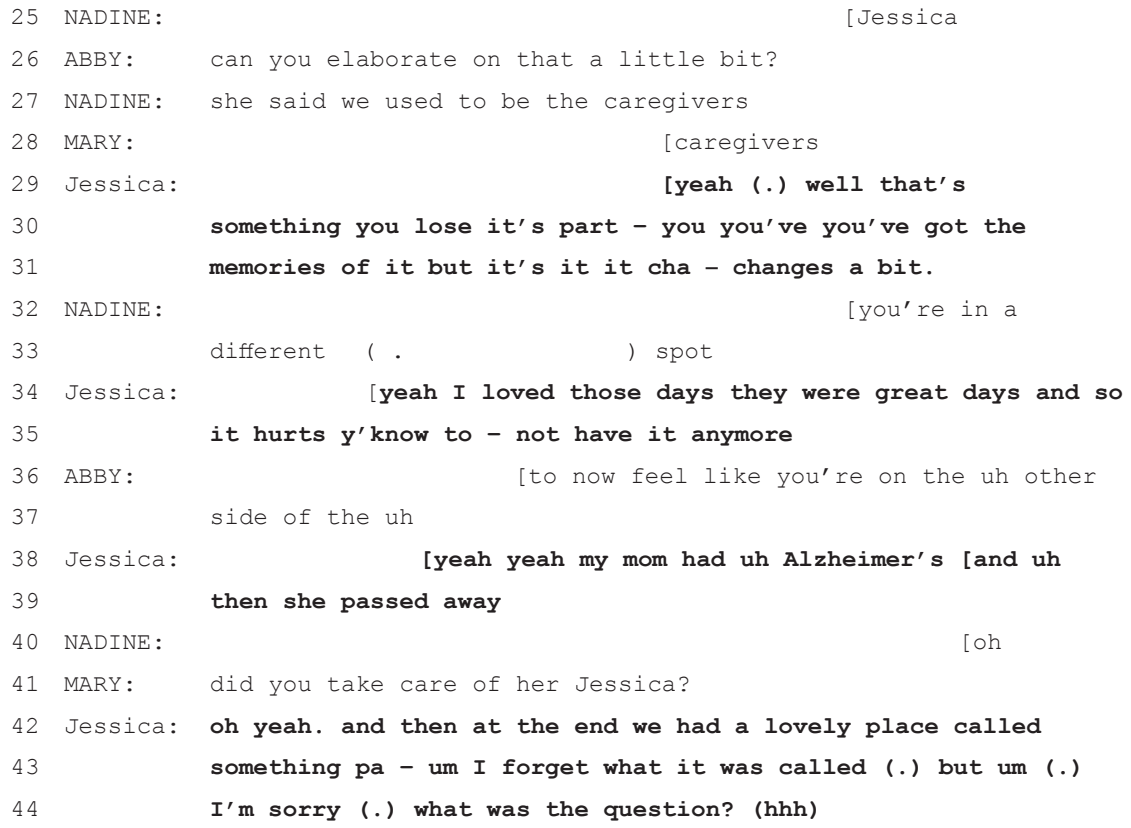

Jessica's subsequently repeated comment (this time loud enough for all to hear) then launches two different discourse trajectories at a figurative "fork in the road": 1) the taking up of a personal stance toward what Jessica just said, as indicated in lines 22-23 by Marcie's relatively dismissive stance; and 2) a narrative orientation toward Jessica's comment, as indicated by Abby's validating comment (line 24) and subsequent request for elaboration ${ }^{5}$ (line 26). Underlying Abby's moves is a recognition that Jessica's comment has refocused the discourse topic from matters related to the facilitators' here-and-now experiences to matters related to support-group members' there-and-then experiences - and that a story may indeed be lurking under the surface of the conversation.

The turns that immediately follow are highly consequential for the development (or not) of Jessica's story. Imagine if others had responded explicitly to Marcie's comments or if they had followed her lead in providing their own personal perspectives on having served as caregivers in the past. Instead, Nadine and Mary respond more immediately than Jessica herself to Abby's request, albeit (interestingly) simply repeating without any elaboration what Jessica had originally said (lines 27-28). Before their turns come to possible completion points, Jessica overlaps their talk and reenters the discussion (lines 29-31) to provide her elaboration. Although the language she uses to convey additional insights to Abby contains evidence of communicative challenges associated with dementia (e.g., semantically weak lexical items such as "something" and "part," repetition, and self-repairs; see Rochon, Leonard, and Goral 2018; Hamilton 2019), several clues in her 
language choices ("lose," "you've got the memories of it," and "changes a bit") appear to provide topical hooks related to change over time that others could build upon, as evidenced by Nadine's proffered reformulation in line 32-33.

Consistent with the approach highlighted above, in what follows we observe that Jessica's single "fleeting" utterance ("we used to be the caregivers") is recognized as a "tellable" (Sacks 1992) that could be transformed into a story - and that interlocutors hold the key through their vigilant attention to the narrative possibilities in what their partner is saying. In lines 34-35, Jessica begins to fill in elements of the distant world underlying the story by conveying a strong positive affective stance toward that time ("I loved those days"; "They were great days"), contrasting her life in the hereand-now with her life in the there-and-then through poignant language ("it hurts y'know to - not to have it anymore"). At this point in the unfolding of the storytelling process, group members learn more about Jessica as a figure in that distant world, but are not yet aware of other foundational building blocks of that world; e.g., for whom she was a caregiver; what actions she performed as a caregiver; and where and when she carried out her caregiving responsibilities.

Abby enters the discussion during Jessica's pause ("it hurts y'know to - ") in line 35 in an apparent attempt to finish Jessica's thought as to what "hurts," although their overlapping continuations in lines 35-36 display slightly different understandings of the contrasting feelings ("to not have it anymore" vs. "to now feel like you're on the uh other side of the uh"). In lines 38-39, then, Jessica latches onto Abby's proposal to divulge the core of the story: "my mom had uh Alzheimer's and uh then she passed away." And, although Jessica does not explicitly tie this utterance about her mother's health to her own role as "caregiver," Mary provides her with the opportunity to make this connection via her question in line 41 ("did you take care of her Jessica?"). In lines 42-44, then, Jessica begins to fill in temporal and spatial details of the world in which she was a "caregiver": focusing "at the end" of her mother's life where she had lived in "a lovely place." As Jessica attempts to provide greater specificity to her account, she runs into two kinds of memory challenges: 1) not being able to recall the name of the "lovely place" ("I forget what it was called"); and 2) forgetting the question that Mary had just posed a few seconds earlier ("I'm sorry (.) what was the question?").

It is in response to Jessica's interactional troubles that we note Mary's high degree of professional training and skillful sensitivity. Rather than, say, (meta)commenting on Jessica's forgetfulness, in lines 45-46 Mary simply repeats her earlier question with two changes: 1) a greater level of semantic precision, replacing the pronoun "her" in line 41 with "your mother" in lines 45-46; and 2) shifting from an unmarked yes-no question to an assertion that assumes the underlying proposition to be the case. 


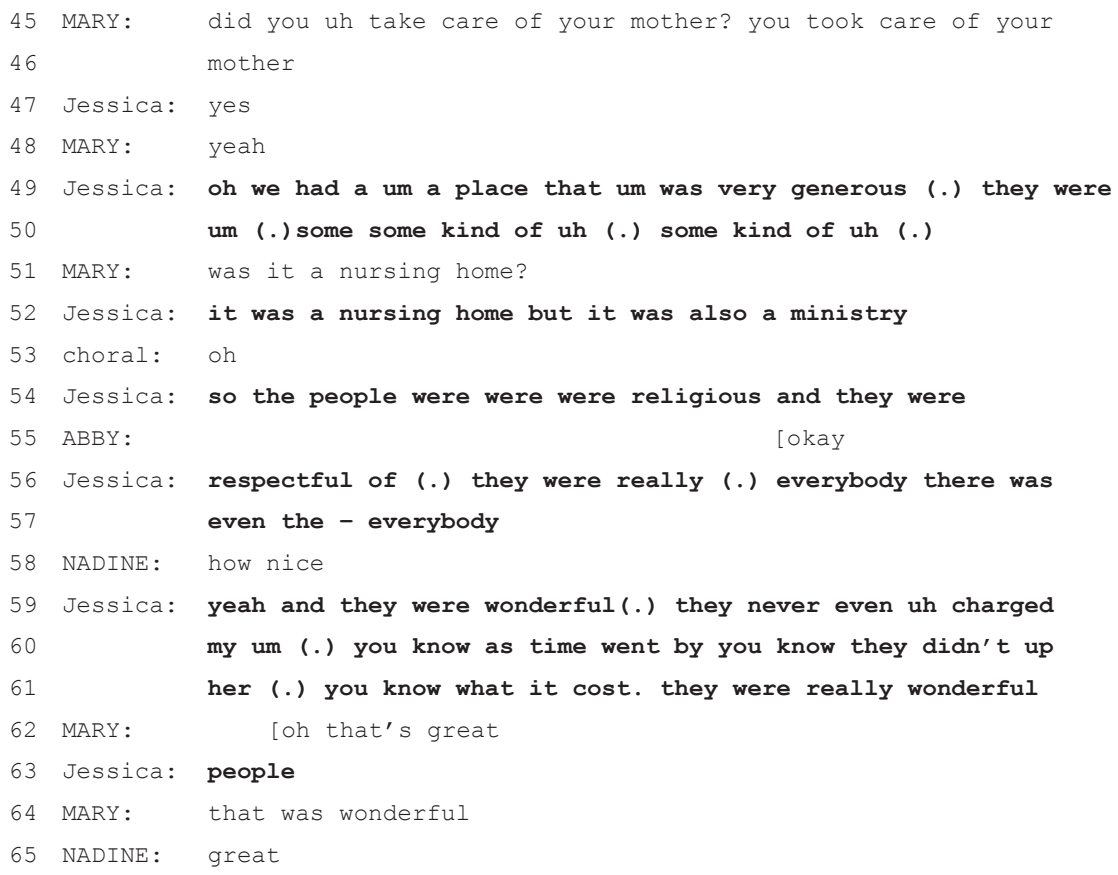

Unfortunately, Jessica's second attempt to respond to Mary does not extend much further than her first attempt; in line 49 interlocutors learn only that the "place" was not only "lovely" but also "generous" before Jessica runs into another word-finding challenge, when she tries to characterize the "kind of place" it was ("they were um some some kind of uh some kind of uh.."). Again, it is Mary who steps in in line 51 with a candidate answer ("was it a nursing home?").

This scaffolding strategy appears to assist Jessica, who not only repeats the offered lexical item but provides the additional detail that it was "also a ministry" (line 52) followed by other associated details regarding the people who populated the "place"; i.e., that they were "religious" (line 54), "respectful" (line 56), and "wonderful" (lines 59, 61). In lines 59-61, interlocutors begin to learn more about the kinds of actions that would have led Jessica to assert in line 49 that the "place" was "generous"; although Jessica's communicative challenges again get in the way of understanding explicitly what these actions were, lines 59-61 contain enough clues to help interlocutors infer that Jessica's very positive view of the place where her mother lived had to do with how the institution dealt with the fee structure for her mother's care ("they never even charged my um (.) you know as time went by you know they didn't up her (.) you know what it cost”). In lines 62-65, then, the topic of "Jessica as caregiver" winds down as Mary and Nadine align with Jessica in their positive stance toward the situation Jessica has been describing. 
Similar to the "dinner rolls" story above, what we observe in this extract is a PWD, Jessica, who manages to contribute to a multiparty discussion with the assistance of others in the interaction. In contrast to the "dinner rolls" story that was introduced by the spouse of the PWD, in this case Jessica introduces within a larger discussion of dementia caregiving a single poignant and relevant observation that, although the individuals in the support group are currently care receivers, they have themselves been caregivers in the past. ${ }^{6}$ Again, in contrast to the "dinner rolls" story, no one in the support-group interaction shared the specific epistemic domain that Jessica was referencing; all needed to draw on a variety of strategies to bring to the surface what underlay the comment.

The initial heavy lifting to launch the story was carried out by group facilitator Abby who oriented to Jessica's single comment as a portal to an underlying experience that had the potential to become a more expansive story as the discussion ensued. By selecting Jessica's comment (rather than, say, Marcie's response to Jessica in lines 22-23) as worthy of continued attention (lines 24, 26), Abby opened up a space for Jessica to continue to talk, sparking subsequent reformulations of her talk by Nadine (line 32-33) and Abby (lines 36-37). Once the heart of Jessica's story emerged, Mary then stepped in to build explicit connections across Jessica's utterances (line 41 ), to maintain a sense of normalcy in the display of memory loss (line 45-46) and to aid in a word search (line 51). And in efforts to make collective sense of the story and to move it toward closure, Abby, Nadine, and Mary all took up epistemic (lines 53, 55) and affective stances (lines 58, 62, $64,65)$ toward aspects of Jessica's story.

With the assistance of these others, Jessica drew on her own specific experiences as an adult daughter caring for her own mother to make a more general point - "we used to be the caregivers" - within a wide-ranging discussion carried out primarily by dementia care professionals within an institutional setting. That said, as we follow the trajectory of the initial voicing of "we used to be the caregivers" in line 19 through the concluding stance-taking to elements of the story in lines 64-65, it is important to recognize the limits of even these well-intentioned discursive efforts of Jessica's interlocutors. Despite these professionals' strategies to support Jessica's contributions to the multiparty discussion, the resulting story that emerges within the interaction contains very little detail: interlocutors come away with a generally uplifting sense that she enjoyed her caregiving experiences within a wonderful residential facility in which her mother lived out the end of her life.

\section{Discussion}

In his multi-faceted and insightful examination of collaborative storytelling in dementia, Hydén provides the following characterization of the link 
between dementia-related communicative and cognitive changes and PWDs' sense of self:

These challenges and changes result in new relationships between the person, his or her body, the world, and other persons. In particular, the person with dementia moves from an experience of being a relatively autonomous individual, to becoming dependent on others in a shrinking world, and with a waning sense of agency.

(Hydén 2018, 176)

It is this trajectory from relative autonomy to interdependence with others that has centered our theoretical and analytical attention on storytelling within multiparty casual and institutional interactions. As we examined how Laura and Jessica recounted family stories from times past that related in clear ways to their lunchtime and support-group interactions in the hereand-now, we hope to contribute to a more nuanced understanding of "how persons tell stories together and in what ways the presence of dementia alters how persons collaborate" (Hydén 2018, 117).

Despite the differences in storytelling situations represented in the two cases analyzed above, we note that Laura's and Jessica's interlocutors made use of similar discursive practices to support their contributions to multiparty interactions:

1) inviting a contribution from a PWD (e.g., How was it with your father's eh family, Laura, you can tell about ...)

2) amplifying/reformulating a PWD's utterance (e.g., You're in a different (.) $s p o t$ )

3) asking a PWD to clarify or elaborate on a previous utterance (e.g., That's a very good point, Jessica.. can you elaborate on that a little bit?)

4) asking a clarification or follow-up question (e.g., Did you ub take care of her, Jessica?)

5) assisting with a PWD's word search (e.g., Was it a nursing home?)

6) repeating a previous utterance without calling explicit attention to the memory gap when the PWD indicates it has been forgotten (e.g., but how was it when they sat down at the table - eh Laura, have you told about the dinner table?)

7) evaluating/taking up a stance toward the PWD's contribution (e.g., That was wonderful)

In addition to these active strategies, interlocutors in both our cases also helped to create an environment conducive to verbal contributions by the PWD by "doing nothing" verbally; i.e., by holding off on the taking of a turn-at-talk even in the face of long pauses. By remaining silent (e.g., resisting the proposal of a "missing" word or attempting to complete the PWD's clause), these interlocutors provided discursive space to the PWDs to 
continue to talk, even if that subsequent talk displayed evidence of the influence of dementia (e.g., extended pauses and repetitions). They also encouraged the storytelling by producing continuers, assessments (ob dear) and other displays of interest and attention, such as laughter and nods.

The analysis has also identified practices that may hamper or derail the storytelling. In the first case, it was a request for elaboration on the background information provided in the story that expanded the insertion sequence to a point where it became difficult for the PWD to resume the story. Furthermore, the husband's code-switching to her weaker language, Norwegian, may have complicated the task for her. In the second case, it was a self-oriented comment by an interlocutor who did not orient to the story potential of the topic and could quite easily have derailed the story before it had a chance to be launched. We note then that interlocutors' contributions that do not directly support and encourage the storytelling in progress may lead to missed opportunities for storytelling or to stories being abandoned and derailed along the way.

The two cases reveal several kinds of opportunities and challenges that may arise in these different types of settings. In cases where the PWDs are in the company of spouses or others with whom they share considerable personal background knowledge, interlocutors may identify opportunities for the PWD to tell a story and elicit it by producing a story prompt. The danger here is that spouses may be tempted to tell the story for the PWD, given their epistemic access to it and the likelihood that they would be able to tell it more fluently. So in relation to such situations, our case illustrates a spouse who consistently orients to the PWD's right and obligation to tell the story despite her apparent difficulties in carrying out the task. Within institutional settings, where conversation partners typically do not typically know a great deal about each other's lives, it may be difficult for these interlocutors to identify opportunities for the PWD to tell personal stories. Our case demonstrates professionally trained facilitators skillfully identifying the story potential behind a conversational contribution that was not itself presented as a story preface and subsequently eliciting a personal narrative by requesting elaboration and asking topicalizing questions.

Our findings suggest ways in which interlocutors' discursive strategies may be used to promote personal agency and feelings of well-being in PWDs who are managing symptoms related to memory and language. Interactional moves that encourage PWDs to launch and tell their stories within complex multiparty interactions may thereby not only help PWDs to display their own personal authoritative knowledge in the conversation, but - by serving to spark memories of historical and personal relevance in others in the group - may ultimately construct a more integrated and inclusive environment for all parties. These supportive topic-building strategies may, then, creatively and compassionately lead to heightened levels of well-being for PWDs, as they discern that their individual expression is connected to enhanced social interaction more generally. 


\section{Jan Svennevig and Heidi E. Hamilton}

\section{Acknowledgements}

We would like to thank the members of the research network Dementia, Language, Interaction and Cognition (DELIC) for discussions on the data used here, and especially Elin Nilsson and Anna Ekström for useful comments on a draft of the article. This work was partly financed by the Research Council of Norway through its Centres of Excellence funding scheme, project number 223265, as well as project number 250093 (JS) and supported by a Humboldt Research Award (HH).

\section{Notes}

1 The transcriptions comply to standard CA conventions (Jefferson 2004). Laughter quality is indicated by $£$ signs before and after the words or sounds concerned.

2 Here and other places in the story, Laura seems to have some problems with referential expressions. In this case, she seems to be talking about her grandfather and not her father, probably alluding to his fertility.

3 Again, Laura seems to have some reference problems in that she refers to "we" rather than "they."

4 In this and subsequent excerpts, names of support group facilitators and the visiting expert in dementia care are spelled in all capital letters to contrast with names of individuals with dementia.

5 Note that Abby does not build on Marcie's comments in lines 22-23 but instead reaches back to Jessica's stand-alone comment in line 19.

6 In order to begin to fathom the degree of courage this interactional move required of Jessica, it is important to "listen in on" Jessica's contribution to Mary's understanding of life with dementia much earlier in the hour-long meeting when she related her reluctance to talk: "I have memory loss and um it's it's embarrassing you know when (.) when you're telling somebody something and (.) I forget names (.) and you forget the person's name after you've given the whole synopsis of what you know they mean to you."

\section{References}

Backhaus, P. 2018. "Reclaiming Agency in Resident-Staff Interaction: A Case Study from a Japanese Eldercare Facility.” Discourse Studies 20: 205-220.

Crichton, J. and T. Koch. 2011. "Narrative, Identity and Care: Joint Problematisation in a Study of People Living with Dementia.” In Discourses of Deficit, edited by C. Candlin and J. Crichton, 101-118. Basingstoke: Palgrave Macmillan.

Goodwin, M.H. 1997. "By-play: Negotiating Evaluation in Storytelling.” In Towards A Social Science of Language, edited by G.R. Guy, C. Feagin, D. Schiffrin, and J. Baugh, 77-102. Amsterdam/Philadelphia: Benjamins.

Gumperz, J. 2015. "Interactional Sociolinguistics: A Personal Perspective." In Handbook of Discourse Analysis, 2nd edition, edited by D. Tannen, H.E. Hamilton and D. Schiffrin, 309-323. Oxford: John Wiley \& Sons, Inc.

Hamilton, H.E. 2008. "Narrative as Snapshot: Glimpses into the Past in Alzheimer's Discourse." Narrative Inquiry 18: 53-82.

Hamilton, H.E. 2019. Language, Dementia and Meaning Making. Cham: Palgrave Macmillan. 
Hamilton, H.E. and M. Baffy. 2014. "Preparing for Performance: Identity Shaping through Script Editing in an Early Memory Loss Support Group.” In Dialogue and Dementia: Cognitive and Communicative Resources for Engagement, edited by R. Schrauf and N. Müller, 213-244. New York: Psychology Press.

Heritage, J. 2012. "Epistemics in Action: Action Formation and Territories of Knowledge." Research on Language and Social Interaction 45: 1-29.

Hydén L.-C. 2011. "Narrative Collaboration and Scaffolding in Dementia.” Journal of Aging Studies 25: 339-347.

Hydén L.-C. 2018. Entangled Narratives: Collaborative Storytelling and the Re-imagining of Dementia. New York: Oxford University Press.

Hydén, L.C. and L. Örulv. 2009. "Narrative and Identity in Alzheimer's Disease: A Case Study.” Journal of Aging Studies 23: 205-214.

Jefferson, G. 2004. "Glossary of Transcript Symbols with an Introduction." In Conversation Analysis. Studies from the First Generation, edited by G. Lerner, 13-34. Amsterdam: Benjamins.

Kitwood, T. 1997. Dementia Reconsidered: The Person Comes First. Berkshire: Open University Press.

Landmark, A.M. and J. Svennevig. forthcoming. "Initiating and Pursuing a Topical Agenda with Limited Communicative Resources.” In Interaction and Dementia: From Diagnosis to Daily Discourse, edited by P. Muntigl, D. Jones and C. Plejert. Cambridge: Cambridge University Press.

Leibing, A. 2006. "Divided Gazes: Alzheimer's Disease, the Person within, and Death in Life." In Thinking about Dementia: Culture, Loss, and the Anthropology of Senility, edited by A. Leibing and L. Cohen, 240-268. New Brunswick: Rutgers University Press.

Lerner, G.H. 1992. “Assisted Storytelling: Deploying Shared Knowledge as a Practical Matter.” Qualitative Sociology 15: 247-271.

Mandelbaum, J. 1989. "Interpersonal Activities in Conversational Storytelling." Western Journal of Speech Communication 53: 114-126.

Mazeland, H. and M. Huiskes. 2001. "Dutch 'But' as a Sequential Conjunction: Its Use as a Resumption Marker." In Studies in Interactional Linguistics, edited by M. Selting and E. Couper-Kuhlen, 141-169. Amsterdam: John Benjamins.

Nilsson, E. 2017. "Fishing for Answers: Couples Living with Dementia Managing Trouble with Recollection." Educational Gerontology 43: 73-88.

Nilsson, E., A. Ekström, and A.R. Majlesi. 2018. "Speaking for and About a Spouse with Dementia: A Matter of Inclusion or Exclusion?” Discourse Studies 20: 770-791.

Österholm, J.H. and C. Samuelsson. 2015. "Orally Positioning Persons with Dementia in Assessment Meetings." Ageing \& Society 35: 367-388.

Ottesjö, C. 2005. "Iallafall som diskursmarkör [Anyway as a Discourse Marker]." In Samtal och grammatik. Studier I svenskt samtalsspråk. [Conversation and Grammar. Studies in Swedish Conversational Language], edited by J. Anward and B. Nordberg, 201-230. Lund: Studentlitteratur.

Ramanathan, V. 1995. “Narrative Well-formedness in Alzheimer's Disease: An Interactional Analysis Across Settings." Journal of Pragmatics 23: 395-419.

Raymond, G. and J. Heritage. 2006. "The Epistemics of Social Relationships: Owning Grandchildren." Language in Society 35: 677-705.

Rochon, E., C. Leonard, and M. Goral. 2018. "Speech and Language Production in Alzheimer's Disease." Aphasiology 32: 1-3. 


\section{Jan Svennevig and Heidi E. Hamilton}

Sacks, H. 1992. Lectures on Conversation, edited by G. Jefferson. Oxford: Blackwell. Sacks, H. 1974. "Some Considerations of a Story Told in Ordinary Conversation." Poetics 15: 127-138.

Schegloff, E.A. 2007. Sequence Organization in Interaction. A Primer in Conversation Analysis. Cambridge: Cambridge University Press.

Schrauf, R. and N. Müller, eds. 2014. Dialogue and Dementia: Cognitive and Communicative Resources for Engagement. New York: Psychology Press.

Selting, M. 2017. "The Display and Management of Affectivity in Climaxes of Amusing Stories. Journal of Pragmatics 111: 1-32.

Seuren, L.M., M. Huiskes, and T. Koole. 2016. "Remembering and Understanding with Oh-prefaced Yes/No Declaratives in Dutch." Journal of Pragmatics 104: 180-192.

Shenk, D. 2005. "There was an Old Woman: Maintenance of Identity by People with Alzheimer's Dementia." In Alzheimer Talk, Text, and Context, edited by B.H. Davis, 3-17. New York: Palgrave.

Sidnell, J. and T. Stivers, eds. 2013. The Handbook of Conversation Analysis. Oxford: Wiley-Blackwell.

Stivers, T. 2008. "Stance, Alignment, and Affiliation During Storytelling: When Nodding Is a Token of Affiliation." Research on Language \& Social Interaction 41: 31-57.

Svennevig, J., P. Hansen, H.G. Simonsen, and A.M. Landmark. 2019. "Codeswitching in Multilinguals with Dementia: Patterns across Speech Contexts." Clinical Linguistics \& Phonetics 10-11: 1009-1030. doi:10.1080/02699206.2 019.1600170

Williams, V., J. Webb, S. Dowling, and M. Gall. 2019. "Direct and Indirect Ways of Managing Epistemic Asymmetries when Eliciting Memories.” Discourse Studies 21: 199-215.

Wray, A. 2020. The Dynamics of Dementia Communication. Oxford: Oxford University Press. 